\title{
STRATEGIC CONTENTS AND EVOLUTION OF ONLINE-OFFLINE \\ ECOSYSTEM IN NEW INTERNET ECONOMY: A COOPETITION
}

\section{CONTEXT PERSPECTIVE}

\author{
Qiang Zhang \\ Shanghai University of Engineering Science, P. R. China \\ Yan Wang \\ Shanghai Business School, P. R. China
}

\begin{abstract}
New-generation information and communication technologies and concurring socioeconomic changes trigger the emergence of online-offline ecosystem as new way of organizing business. Treating business model as the gene of business ecosystem to cope with external technological and socioeconomic pressure, we propose a coopetition context framework which emphasize the strategic importance of contexts in building online-offline ecosystem, and a classification of business models in the context of new internet economy. Utilizing China in its mobile internet era as the specific empirical setting, we address strategic features, context structure and developmental prospects of main type online/offline business models, and study the combinability and long-term competitiveness of the business models to delineate the evolutionary path of the mega online-offline ecosystem.
\end{abstract}

Keywords: Online-offline ecosystem, coopetition context, business model, evolution

JEL code: L22, M15

\section{Introduction}

Information and communication technology (ICT), such as smart communication terminals, low-cost internet infrastructures and open source software, is changing societal life and business practices (Scoble and Israel, 2014). In the past decade, the new generation of mobile information and communication technology emerged and developed rapidly, causing dramatic changes, e.g., "internetization" (Etemad, Wilkinson and Dana, 2010) in the way that consumption and business are carried out, and relevant regulative actions, e.g. the "Internet Plus" program in China, which reflects the upgrading of industry policies in the new ICT era (Wang et al., 2016; Hong, 2017).

New technologies and simultaneous changes in societal and market spheres lead to the empowerment of consumers, and increased social embeddedness of market competition 
among product and service providers. All these call for more effective ways of organizing production with more emphasis on the co-evolutionary tendency between new ICT technology and its societal, business and policy surroundings. Within such a paradigm of social-economy-technology co-evolution, the concept of "ecosystem" is particularly meaningful (Moore, 1993; Iansiti and Levien, 2004). Recently, economy and management researchers have begun to utilize the theory and strategic thinking of ecosystem to reveal micro-level or industry-level phenomena of internetization (i.e., Yang and Wang, 2013; Huang, Pan, and Liu, 2017), but seldom attempt to adopt these views to a more large scale and complex setting, that is, to clarifying strategic issues of evolving the economy under internetization as an ecosystem.

The current study contributes to fill these gaps in the literature. Theoretically, we introduce an integrative perspective that synthesizes theoretical pieces that treat ecosystem as cooperation-competition (coopetition) device to create collective value (Iansiti and Levien, 2004), or societal-cultural fields reproducing particular coercive, mimetic and cognitive rules relations that determines the subject position and potential gains of players connected with the ecosystem (Thomas and Autio, 2014), and propose several research questions and research framework to accomplish these.

We utilize China as the distinct setting to reveal strategic implications of adopting such an integrative perspective. Specifically, we begin with a brief review on the macro environment of internetization in China to reveal pressures for changes, and carry out analysis regarding (1) typology of online-offline business models, (2) strategic mix of the proposed business models, and (3) the developmental tendency of these business models and the evolutionary paths at the online-offline ecosystem as the aggregation of these business models.

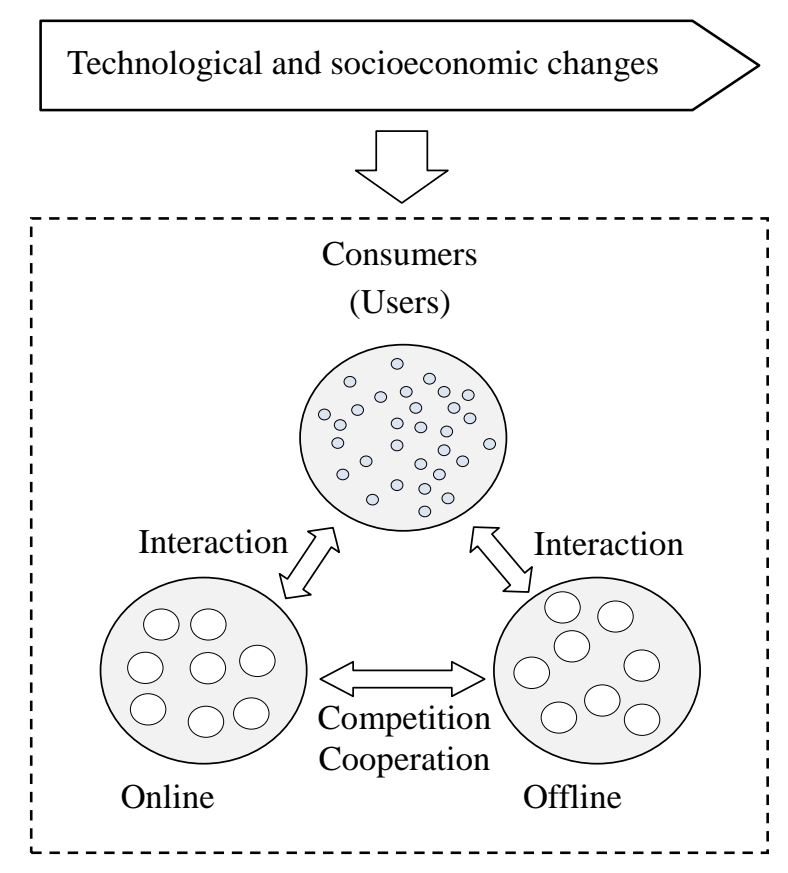

Figure 1. Mega online-offline ecosystem in new internet economy 


\section{Research Perspective and Framework}

\subsection{Business and consumption as a mega online-offline ecosystem}

Business and consumption in the era of mobile internet mainly involves three kinds of sub-populations: consumers (users), online companies and offline companies. Internal interactions within sub-populations (intra-subpopulation interactions) and interactions among subpopulations (inter-subpopulation interactions) constitute the macro socioeconomic environments (i.e., at the national level) as a mega ecosystem in the context of new internet economy (see Figure 1). The mega ecosystem consists of many business ecosystems dominated by online or offline companies (the so-called focal companies).

To emphasize our focus on business and strategy, the current study chooses to ignore co-evolutionary relationships within the sub-population of consumers. Instead, we utilize the concept of business model to characterize "characteristics and trends" of business in new internet economy, regarding the business model (interaction-based strategy) and the mega ecosystem (the overall features). The mega ecosystem functions as the collection of business models, evolving itself in the process of business model upgrading.

Specific topics dealt in the current study include: (1) prosperity and decline of different business models within the online and offline business sub-populations (intra-subpopulation level), (2) the overall situation of the competition and the cooperation between the online companies and the offline companies (inter-subpopulation level), and (3) the overall evolution of the mega ecosystem (ecosystem level).

\subsection{Business model as gene of the mega ecosystem}

Business model, if put it simply, refers to common features of strategic actions adopted by a number of companies within a given market field. Those companies which adopt a same business model form a "strategic group" (Dess and Davis, 1984), or "subpopulation" in an ecological sense. Business models (sub-populations) in new internet economy can be divided into two basic categories, online business model and offline business model.

Business models for online companies. Business models adopted by online companies can be classified into four categories by the tendency of competition-cooperation (coopetition) and the digitization of consumption experience: (1) "Element-based competition", by which the online company aim to evict offline companies from distinct business fields; (2) "Platform-based integration", by which the online company provide technology platform to dominate offline companies' value-adding processes, (3) "Platform-based cooperation", by which the online company utilize its platform to establish a collective value-adding process with a number of offline companies, and (4) "Service-based cooperation", by which the online company provides supportive services for offline companies to realize the cooperation.

Business models for offline companies. The vigorous development of new ICT and other emerging technologies is also promoting the connection of offline companies to the internet, 
that is, the process of internetization. The strategic choice of offline companies is more complex. One the one hand, the aforementioned four types of online business models can also be adopted by the offline companies, to transfer itself into online companies in whole or in part; on the other hand, the offline companies can be internetized indirectly by means of cooperation (namely becoming the objects of online business models) with the online companies at different levels (e.g., channel-, information- and business model-). In general, offline companies are facing more prominent competitive pressure in the era of new internet, and it is more urgent to upgrade their business models.

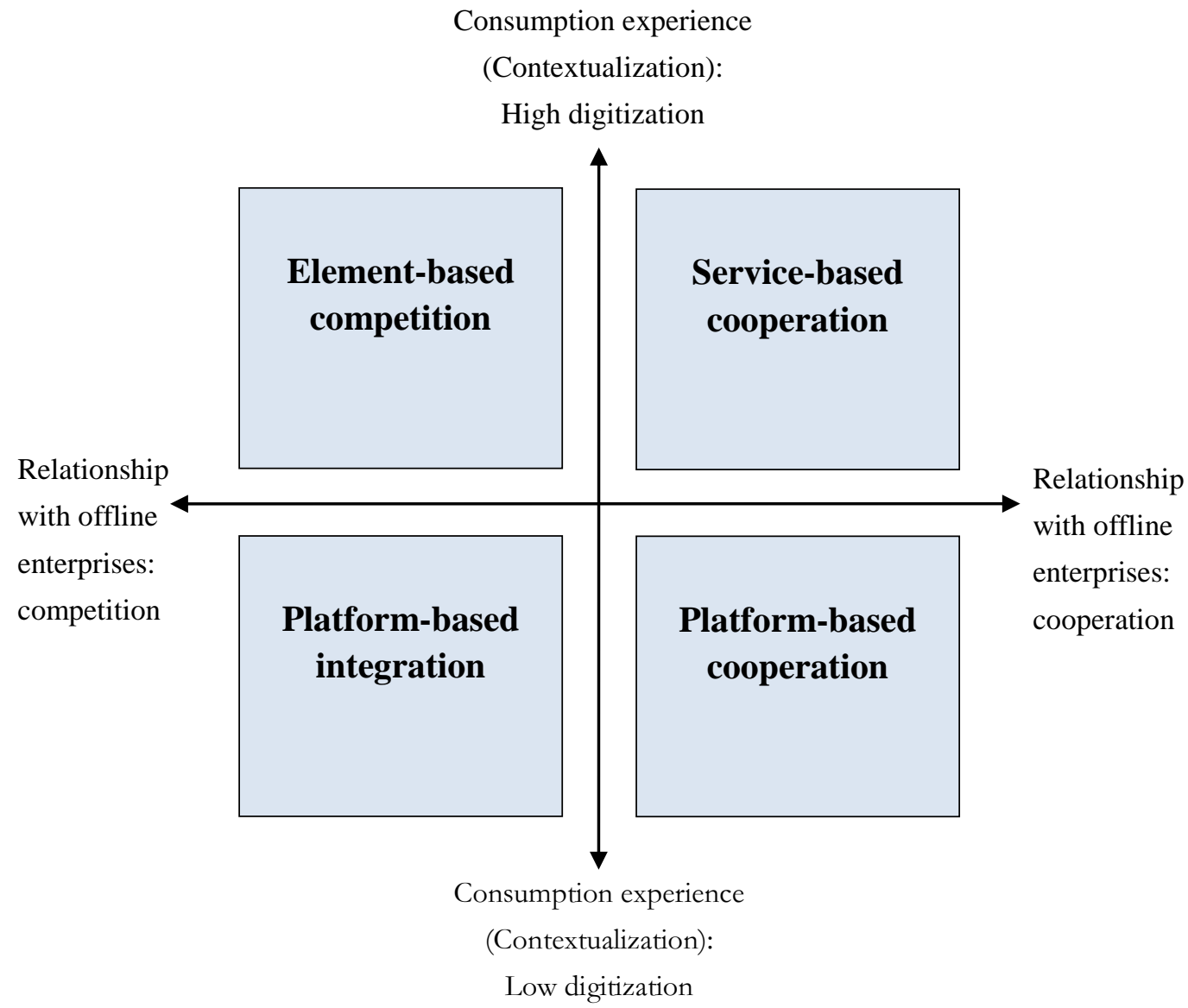

Figure 2. Classification of online business models in new internet economy

Given the constraint of resource mobilization and time-lag of technology commercialization, online business model and offline business model presents an alternative relationship in a short term; under the general trend that empowerment of consumers and integration of new technologies into social life continue to progress, both the online business model and offline business model tend to integrate with each other in a long term.

\subsection{Analytical issues}

\subsubsection{General trend of consumption: SoLoMo}

The basic feature of consumption in new internet economy, which is characterized by new 
generations of mobile communication and information technology, is often described as "SoLoMo", namely "socialization, localization and mobilization". The reason why the concept of SoLoMo is widely accepted by consumers and managers worldwide should be attributed to its theoretical forward-looking. First, SoLoMo predicts the general trend of change in consumer demand and behavior in the mobile Internet era from the vision of "integration between the Internet and social life". Second, SoLoMo summarizes the possible path for the consumers to achieve their autonomy in the mobile Internet era. "Socialization"- e.g., online social networks - changes the way by which consumers exchange information about product and service; "Localization" urges Internet companies to invest more into constructing "offline scenario"; "Mobilization" enables consumers to shop, make friends and learn using mobile devices and smart platforms.

\subsubsection{Essentials of online/offline strategies: Contextualization}

Consumption contextualization. SoLoMo means that the way to meet the demands of consumers (users) is constantly migrating from offline to online. Consumers will pay more attention to digitization of the context shaping their consumption experience-i.e., enjoying "buying anything at anytime and anywhere"-which is made feasible by new internet and digital technologies. In this regard, Scoble and Israel (2014) have more detailed description. They suggest that the technology base of SoLoMo includes five typical elements, "Big Data, Mobile Communication Device, Social Media, Sensor and Positioning System". As the discourse power of consumers in market constantly enhances, the scope of digitized consumption contexts they expect will continue to expand. Consumers will no longer be satisfied simply by the offline interaction with product providers when shopping, but will try to project their influence to deep their involvement in value creation of the product.

Business contextualization. In response to the strong involvement in the business activities by consumers, companies need to link their business activities to consumers' demands deeply to realize "business contextualization". Contextualization of business activities in the context of new internet means that the business model has undergone tremendous changes, from informationization to internetization. In the context of mobile internet, allocation of the computing power and collection of data are becoming the infrastructure as electric power, while the traditional, large-scale hardware investment based on the informatization thinking becomes unnecessary. As a result, large and small, online and offline companies require a quasi SDN (Software Defined Network) thinking to build a more flexible, motile and resilient IT infrastructure by innovations of utilizing external ICT infrastructure service resources to ensure the synchronous evolution between them and the technology and commercial consumption.

Internetization of value chains as the method. Specifically, contextualization of consumption and business means the internet-based innovation throughout the value chain. In current days, internetization mainly occurs at the surface level of the value chain (stages such as sales and service which are closely related to individual consumption, corresponding to "consumption contextualization"), and formalized new application service fields, such as 
mobile shopping, mobile internet finance, mobile education, and mobile media. With the development of new internet technology and business model innovation, internetization is developing to the middle and front stages of value chains (such as manufacture, design and idea creation, corresponding to "commercial scenario").

"Industry 4.0" and "Internet Plus" in China. Contextualization of consumption and business, as the common vision of the society and the market, reflects in the formulation of national strategy in relevant areas. From the perspective of industry and informatization development, China has embarked on the formulation and implementation of the 10-year action program and roadmap for "made in China 2025" (China's "Industry 4.0'). At the level of the national economy, the contextualization of consumption and business represents as the indefinite boundaries in business scope between online companies (internet companies) and offline companies (traditional companies), and the increasing degree of overall internetization of the industry. The Chinese government has proposed its "Internet Plus" plan in 2015, indicating the "integration between online and offline" officially rising to the national strategy.

Given general trends in the macro environments, SoLoMo, consumption and business contextualization, and online and offline integration as mentioned above, the current study concentrate its efforts to demonstrate the future trend of China's mega ecosystem of business and consumption in the context of mobile internet. Specifically, by delineating key features, typical cases and development trend of main business models by China's online and offline companies in the era of mobile internet. Online companies and offline companies compete and cooperate with each other by introducing and combining different types of business models, and it ultimately leads to the change in the position of the online companies and offline companies in the ecosystem of the mobile internet (mega ecosystem) so that the ecosystem structure of the mobile internet business constantly evolving, and transiting from "old equilibrium" to "new equilibrium". By such, the current study provides a full map regarding the evolution of China's mobile internet business ecosystem, by focusing on temporal changes in the position of different business models.

\section{Classification of Business Models in New Internet Economy}

\subsection{Classification}

\subsubsection{Main dimension}

First of all, business models can be classified into online context-based business model and offline context-based business model in accordance with the degree of internetization. As discussed above, online context is "virtual" compared with offline context, and its core value is derived from specific technological elements such as mobile internet, cloud computing, big data and LBS, which have been highlighted the embodiment in existing mobile business models such as group buying, map service, etc. Second, value chain itself is a collection of contexts-including "foreground" consumption contexts (narrowly defined categories of 
marketing) that are closely related to consumers, and "background" business contexts (R\&D, production, sales, logistics, etc.) that are relatively distant from the consumer.

\subsubsection{A classification based on business and consumption contexts}

We summarized six main business models based on contextual interaction under the background of mobile internet, including online business models (platform-based integration, platform-based cooperation, element-based competition and service-based cooperation) and offline business models (Online-to-Offline [O2O] and traditional). Besides, distinct businesses may take one, or a combination of different types of business models (Table 1).

Table 1. Groups and business models of mobile internet ecosystem

\begin{tabular}{|c|c|c|c|}
\hline Groups & Subgroups & $\begin{array}{l}\text { Relationship } \\
\text { offline/online } \\
\text { companies }\end{array}$ & Features of main business models \\
\hline \multirow[t]{4}{*}{$\begin{array}{l}\text { Online } \\
\text { companies }\end{array}$} & $\begin{array}{l}\text { Integrated } \\
\text { platform } \\
\text { companies }\end{array}$ & $\begin{array}{l}\text { Competition } \\
\text { (Integration) }\end{array}$ & $\begin{array}{l}\text { [Platform-based integration] build integration } \\
\text { advantage by entering the value chain of } \\
\text { offline companies }\end{array}$ \\
\hline & $\begin{array}{l}\text { Cooperative } \\
\text { platform } \\
\text { companies }\end{array}$ & Cooperation & $\begin{array}{l}\text { [Platform-based cooperation] Cooperate with } \\
\text { offline companies to form the value chain } \\
\text { together with the offline companies }\end{array}$ \\
\hline & $\begin{array}{l}\text { Service provider } \\
\text { companies }\end{array}$ & Cooperation & $\begin{array}{l}\text { [Service-based cooperation] Establish } \\
\text { partnership with offline companies by } \\
\text { providing supportive services }\end{array}$ \\
\hline & $\begin{array}{l}\text { Element } \\
\text { substitution } \\
\text { companies }\end{array}$ & $\begin{array}{l}\text { Competition } \\
\text { (Substitution) }\end{array}$ & $\begin{array}{l}\text { [Element-based competition] Build } \\
\text { competitive advantage over offline companies } \\
\text { by providing product with better quality }\end{array}$ \\
\hline \multirow[t]{2}{*}{$\begin{array}{l}\text { Offline } \\
\text { companies }\end{array}$} & O2O companies & Coopetition, active & $\begin{array}{l}{[\mathrm{O} 2 \mathrm{O}] \text { Actively compete and cooperate with }} \\
\text { online companies by partially adopting online } \\
\text { business models }\end{array}$ \\
\hline & $\begin{array}{l}\text { Traditional } \\
\text { companies }\end{array}$ & Coopetition, Passive & $\begin{array}{l}\text { [Traditional] Passively compete and cooperate } \\
\text { with online companies with online business } \\
\text { model rarely considered }\end{array}$ \\
\hline
\end{tabular}

Note: Large online companies, especially large-scale integrated platform companies such as Alibaba, Baidu, Tencent adopt a variety of business models in a mixed way; the difference between the $\mathrm{O} 2 \mathrm{O}$ offline companies and traditional offline companies lies in the extent of internetization, and the former has a higher degree of internetization.

\subsection{Evaluating competitiveness of business models}

Such context-based classification of business models, places emphasis on the commonality of the companies in a certain subpopulation and a certain period. The evaluation of business models involves three main aspects: (1) Context structure (such as the proportion of online contexts and offline contexts and the mode of coopetition between the two kinds of contexts; (2) Strategic features (coopetition relationship reflected by contexts and the requirements on the capacity of companies), and (3) Dynamic prospects of the business model. 
Companies impose influence on the target consumers (users) and other companies, by means of introducing or combining different business models to enhance their competitive advantage. The integration effect of such strategic actions leads to a change in the position of such companies in the whole business ecosystem (and the mega ecosystem). To this end, companies shall choose business models which not only meet the external environment requirements, but also match their own resource endowments.

The context structure of the business models should meet the development trend of external technological environment, in particular: (1) The vigorous development of new-generation mobile communication and information technology will enhance the share of digital consumption, therefore the proportion of the online contexts is on the rise on the whole; (2) As the degree of digitization and internetization of offline businesses becomes increasingly higher, the combination mode of online and offline contexts will develop from "mechanical connection" to "organic integration".

Companies need to develop the ability to make their businesses "contextualized". Such capabilities of designing, building and revising the interaction context should be developed comprehensively: (1) IT capacity (including the "basic" IT capability in supply chain management, CRM, resource scheduling); (2) Capability of internetizing the offline contexts, which is not limited to the consumption context, but shall expand to the entire value chain and value adding process; (3) Capability of operating and maintaining original online/offline contexts-"Native" contexts will exist for a long term, which is the resource foundation for contextualization of online/offline companies.

\section{Technological and Socioeconomic Background}

\subsection{Internetization being a key to the development of offline business}

The vigorous development of a new generation of mobile communication and information technology and SoLoMo of consumer demand continue to promote the upgrading of various sectors of China's national economy. In terms of the retail circulation, the latest data of the State Statistics Bureau shows that the national online retail commodity turnover in Q1 of 2015 was RMB 631 billion with an increase of $41.0 \%$, accounting for $8.9 \%$ of total retail sales of social consumer goods. 2014 National Economic and Social Development Statistics Bulletin shows that China's online retail sales in 2014 was RMB 2.7898 trillion with an increase of $49.7 \%$ over the previous year (the annual growth rate of the total retail sales of consumer goods in 2014 is $12.0 \%$ ), occupying $10.6 \%$ of the total retail sales of consumer goods. According to report by IResearch, although the growth speed of China's online shopping market declined (decreased from $70.2 \%$ in 2011 to $48.7 \%$ in 2014), it is still higher than the growth rate of the whole retail market in the same period.

Increasing penetration of e-commerce in various sectors of the national economy and large scale of online retail market, cause damages to the traditional offline retailing sector. 
According to China Chain Store \& Franchise Association (CCFA) reports that the growth rate of sales by Top 100 retail companies declined below $10 \%$ for the first time in 2013 , and that the proportion to the total retail sales of sconsumer goods declined from $11.1 \%$ in 2009 to $8.6 \%$ in 2013 . The diversion effect caused by the rising of network/mobile shopping is very obvious.

\subsection{Integration between online and offline as the inevitable trend}

Influence of internetization is not limited to the above-mentioned retail companies, but includes the whole of the offline companies and the online companies, namely the entire mega ecosystem. Consulting similar phenomenon in the business fields in developed economies, we might provide some general propositions that predict the overall situation of the business development in the context of China's mobile internet.

First, online companies do not have overwhelming competitive advantage over the offline companies (traditional companies). For example, in terms of the scale, the size of China's online shopping market in 2013 was about RMB 1.8925 trillion, which did not reach the total sales of the traditional Top 100 retail businesses in the same period.

Second, the advantage of online companies on the supply chain efficiency and price tend to be reduced when offline companies increase the integration, concentration and supply chain efficiency of the entire retail channel. Taking the US as an example, the overall strong competitiveness of the offline companies inhibits the expansion of the scale of e-commerce: the scale of the e-commerce market in US in 2013 was USD 263 billion, accounting for 5.8\% of the overall retail market, lower than $8.0 \%$, the relevant indicator in China (scale of online shopping market/total retail sales of consumer goods, IResearch).

Third and most importantly, as the online companies and offline companies are entering each other's traditional competition fields, "online-offline competition" is constantly blurring the boundaries of online companies and offline companies as well as manufacturing companies and distribution companies, and changing the structure and direction of evolution of the entire mega ecosystem. We still take America as an example, Favorite 50 e-commerce website ranking shows that among the Top 10 websites are controlled by traditional offline manufacturing/retail companies excluding Amazon (first) and eBay (third). In China, on the one hand, various types of offline companies (retail companies such as Dashang Group and manufacturing \& retail companies such as Metersbonwe) connect to the internet in succession; on the other hand, online companies (such as large e-commerce companies, such as Alibaba and small and medium-sized e-commerce companies, such as Meilele) are "down to earth" by establishing offline experience stores and cooperating with offline stores.

\subsection{Strategic issues in the context of mobile internet}

\subsubsection{Business ecosystem and business model}


As mentioned above, the development of new-generation mobile communication and information technology brings business-wide, omni-channel competition and integration. The mega ecosystem in the context of mobile Internet consists of three subpopulations, i.e. online companies, offline companies and consumers (and their subgroups) (see Fig. 1), while narrowly defined, it refers only to the integration of online companies and offline companies. Online companies and offline companies and their subgroups can be distinguished according to the business model they use (a group of companies that use the same, similar business models are called strategic groups). In other words, change in and evolution of the structure of the business ecosystem is essentially the result of the competition and integration between different online and offline sub-groups and their internal sub-groups. Taking this into consideration, we need to: (1) Define and classify the mainstream business models under the background of mobile Internet; (2) Analyze the competitiveness and development prospect of various types of business models; (3) Analyze penetration of these business models in the online and offline company groups and the change trend to judge the evolution direction of the business ecosystem.

\subsubsection{Business model and contextualization}

Business model, as a broad concept, no doubt can be defined from different point of views. "Contexts" has undoubtedly become the core of the business model under the background of the new mobile internet technology development and SoLoMo. "Contexts" is not a new concept for the companies. After all, consumers' behavior is always performed in a certain context, and more or less, or directly or indirectly, interacts with the companies until a substantial purchase is generated; it emphasizes that the customers' experience and interactive services are already the "standard configuration" of the operation of modern businesses. Although the mainstream business contexts are still "non-ICT" led by the offline companies, the general trend is a digitalized scenario.

In 2013 , more than $60 \%$ of US retailers have taken "omni-channel" as the primary strategy to expand sales. The so-called "omni-channel" is based on company-consumer interaction as the fundamental starting point, and conducts the comprehensively integrated business strategy in virtue of emerging technologies such as the mobile internet to meet the seamless transition of consumers between a variety of virtual (online) and realistic (offline) shopping contexts. This is essentially the operation of the contexts. In China, the leading online and offline companies in various fields since 2013 have begun to plan on the operation of the contexts and taken it as part of the business strategy. For example, Taobao released its $\mathrm{O} 2 \mathrm{O}$ overall strategic planning for the first time at the end of 2013, "bases on the global market and the pattern, takes big data and cloud computing as the link, SNS social marketing as the core of communication, LBS positioning and tracking technology as the basis, omnipresence of mobile internet as the cntext, PC technical system as the support, integration between online and offline companies as the business model, and accurate and personalized satisfied customer experience as the commercial value", and asserts that "the consumers are extremely simple in the future, business contexts are the real core." 


\section{Competiveness and Developmental Trends of Basic Business Models}

In this section, we address strategic features, context structure and developmental prospects of main type business models, and business practices of online and offline companies in China.

\subsection{Online business model}

\subsubsection{Platform-based integration model}

\section{(1) Working definition}

Platform-based integration model refers to the business model, by which the online company (or $\mathrm{O} 2 \mathrm{O}$ offline company) involves in the value chain of offline companies-i.e., by controlling the information flow access-by utilizing the platform. This business model grants the company integration advantages. Platform-based integration model also can be further divided into horizontal integration and vertical integration, according to the scope and depth of integration.

\section{(2) Context structure}

Competitiveness of the business model mainly stems from the so-called channel advantages in the sense of marketing channel, rather than consumer value creation-oriented context construction. Companies adopting such model tend to regard the "online" as the channel entrance for the offline companies to obtain the consumer flow, and therefore motivated to control the entrance of such online-to-offline flow to obtain channel-dominance advantages. Contextualization level of the business model is low, and the integration of online and offline contexts is also at early stage (at the channel integration level).

\section{(3) Strategic characteristics}

Platform closeness. The strategic focus of online companies (or $\mathrm{O} 2 \mathrm{O}$ offline companies) adopting this model is to control the flow entrance, specifically, be creating an internet platform for potential network effect. In this sense, competitors of the online companies (or O2O offline companies) adopting such model are mainly the online companies adopting similar models. Regarding offline companies which are not included in the platform system, the integrated platform company tends to maintain a certain extent of openness of the platform to attract these offline companies.

Dominance of the online company. Offline companies included in the platform ecosystem are often in an absolutely inferior position. Theoretically, offline companies can comprehensively utilize multiple online channels (such as their own e-commerce platform, e-commerce platform operated by online companies and other platforms) to maximize the value of the available online platforms and reduce the risk of over-reliance on a specific platform. However, the implementation of such a channel mixture strategy is not easy: (1) large integrated platforms possess exclusive control and pricing rights over the use of online flow entrance; (2) although the cost for shifting to small and medium-sized online platforms is lower, the information granularity and precision need to be considered; (3) establishing an 
internet platform might grant the offline company relatively stable and large-scale information flow, however it is difficult for the offline company to obtain the required technological capacity and financial capital.

Typical case. Currently, a number of platform-based internet companies, such as Alibaba, Baidu, Tencent have formed a number of self-centered Internet business ecosystems. These ecosystems are more or less characterized by integrated platform model. Taking Alibaba as the example. (1) Alibaba's Taobao Mall, renamed as "Tmall" in January 2012, as the largest online shopping platform in Asia and even the world, and continues to consolidate its dominance to "sellers" (offline companies) connected to the platform. In October 2011, Taobao increased the annual service fee from RMB 6000 to RMB 30,000 and 60,000. At the same time, default margin also increased from RMB 10,000 to RMB 50,000, 100,000 and 150,000 . Releasing such a new rule without extensive communications with sellers resulted in intensive resistance from a large number of small and medium-sized sellers. (2) In July 2013, Alibaba Group issued a statement that "in recent, we discovered that some sellers bothered the users with WeChat marketing application, and even some sellers made use of the application to convert the entire transaction out of Taobao's security payment system, we will suspend the use of WeChat-related applications temporarily in the service market to protect consumers' experience and control the risk of transactions." While cutting off the use of WeChat-related applications in its ecosystem, Alibaba was actively building its mobile instant messaging application, Lai-Wang. (3) In June 2014, Alibaba started the beta test of the Taobao Open Platform. Taobao Open Platform is an open e-commerce service provided by Taobao for third parties. The main contents include: Taobao e-commerce basic services in the form of OpenAPI, Taobao's open application platform, and open basic support for third-party application platform. However, industry experts pointed out that it still needs to prevent the possibility of "market monopoly" even of such open platform from the viewpoint of the entire e-commerce section.

\section{(4) Developmental tendency}

Although the platform-based integration model still has a prominent position in e-commerce and other areas, but its prospects are not too optimistic. First, it does not coincide with the general trend of openness as the fundamental logic of internet and e-business, which assign platform-based cooperation model more favorable position; second, as the legislation in China's mobile Internet and e-commerce advances, policies and regulations against monopoly of any internet platforms will be gradually improved; finally, an increasing number of offline companies are utilizing online models to transform their huge advantages of offline resources to construct distinct competitive advantages over platform-based integration online companies. All these forces make platform-based integration companies consider adjusting their competitive strategies.

\subsubsection{Platform-based cooperation model}

\section{(1) Working definition}

Platform-based cooperation model refers to the situation, in which that the online company 
(or $\mathrm{O} 2 \mathrm{O}$ offline company) conduct equal cooperation with offline companies. In this sense, although the online company has established a platform, it does formalize a dominant position relative to offline companies. In this sense, the platform builder online company participant a value chain together with the offline companies.

\section{(2) Context structure}

For the online company adopting the model, it can integrate some functions of offline companies into its IT-based online platform. Offline companies connect with the platform by embed QR code, mobile payment, online business solutions and other IT system components provided by the online company into its business. In this sense, the online company and offline companies participate in the collective construction of business and consumption contexts: the offline business and consumption contexts are gradually digitized so that the value of online contexts is enhanced; as the number of the embedded technical components increases, the degree of the internetization is also improved.

\section{(3) Strategic characteristics}

"Cooperation + low intensity competition" is the main melody of this model. The online company (or $\mathrm{O} 2 \mathrm{O}$ offline company) adopting the model pay more attention to context management rather than regarding the online platform as a device to seize channel dominance advantages. For offline companies engaged in such a cooperative relationship, the online contexts of its value chain are extended by "embedding" various types of technological components provided by the online company. This model points to an open ideal situation of win-win-"mutual synthesizing between online and offline".

Typical cases. The cooperative feature is reflected in the trend of strategic actions of "Internet Plus (integration of online and offline businesses, i.e. O2O)" of traditional large-scale platform-based internet companies since 2014. Alibaba announced its planning of $\mathrm{O} 2 \mathrm{O}$ strategy at the end of 2013, defining $\mathrm{O} 2 \mathrm{O}$ in the sense of online-offline integration business model with LBS, mobile internet and other information technology systems as the support, the complex commercial chain as the basis and contexts as the core. Tencent does not have advantage in the online e-commerce and offline operation, propagandized its identity as an "O2O overall solution provider", and intended to embed in the core businesses of the offline companies reversely. By the end of 2014, Tencent's open platform has 2.4 million apps involving in various aspects, such as entertainment, life and education, 5 million entrepreneurs covering first- to third-tier cities, and the gross estimate value of the partners of over RMB 200 billion. The platform structure of some platform-based companies is indeed more open, it also has its objective reasons: First, the monopoly of the platform itself as a flow entrance is not prominent (such as the WeChat platform of Tencent compared with Taobao of Alibaba); second, it suffers pressure from the offline companies and online companies adopting other business models, consumers as well as the governments.

\section{(4) Developmental tendency}

Platform-based cooperation model has good developmental tendency. It not only applies to the large-scale platform-based internet companies, but also to the small and medium-sized 
vertical platform dominated by "APP portal" internet-based start-up companies. The model has reasonable market base. Competitive situations favorable to the model include: (1) the improvement of the informatization and internetization capabilities of offline companies; (2) mobile internet-related IT technologies such as QR code and mobile payment entering the mature stage; (3) excessive expansion of by large-scale platform integrator online companies intensifying divided subpopulations within online companies, which makes closure-featured online platforms confronted with increasing competition pressure.

\subsubsection{Service-based cooperation model}

\section{(1) Definition}

Service-based cooperation model is the way by which the online company (or O2O offline company) help offline companies to internetized their offline businesses, i.e., by providing business solution packages to increase the proportion of online contexts and the degree of integration between online and offline contexts. Compared to platform-based cooperation model by which collaborative actions occur at the data level or the channel level, the model reflects high-level cooperative relationship with offline companies, namely cooperating at the business model level. Companies adopting such model include internet companies (platform providers, third-party developers depending on platform and other internet companies) and software service companies.

\section{(2) Context structure}

Companies adopting such model actually become the solution providers of offline companies to enhance the internetization of their offline businesses. At the current stage, offline companies intending to expand online businesses are majorly concerned about internetization of sales (consumption) process of their value chain, building relevant online contexts, such as online shopping, mobile payment, virtual shopping in real stores. However, once the internetization of their offline contexts advances, the focus will be shifted to more vital processes of the value chain. Lacking informatization and system development capacities, offline companies tend to select third party developers, rather than platform providers, as the partner.

\section{(3) Strategic characteristics}

Collaborative relationship with offline companies. Internetization of offline contexts requires the offline companies to disclose key information about value adding processes, to the service provider companies. In this sense, the service provider companies need to establish real collaborative relationship with their entrusting parties, rather than coveting the business contexts and key information of offline companies.

Mutual repellency with the platform-based model. During the process of seeking for service support to internetize their offline contexts, the offline companies will try to avoid the risk of being integrated by the offline company platform. They tend to prefer 'pure' service provider online companies to platform-based online companies. This reflects the mutual repellency between the service-based cooperation model and the platform-based models. 
Therefore, unless the platform-based online companies have the same absolute technical leadership, they need to ensure the openness of the platform if they expect to involve in such service fields. In case their own credit is difficult to guarantee, they should take the initiative to seek an external system to guarantee their commitments and restrict their rights.

Typical cases. By the end of 2014, Yonyou Software, a famous software service provider in China, changed its name to Yonyou Network, marking that its strategic focus officially transfers to providing service for the internetization of Chinese companies. Top management of Yonyou believes that internetization of companies (business) is a combination of business innovation and industrial development and a revolution in doing business; internet service will become the key power for the development of Yonyou. Based on new business concepts as above, Yonyou proposed to provide users with services and establish new cooperative relationship at the following three levels: (1) Platform services. New-generation enterprise computing platform is the IT basis for the companies conducting internetization. The Yonyou UAP platform is created based on new computing architecture, can provide companies with key technology platform support, such as mobile, cloud management, big data processing to substantially increase their IT efficiency; (2) Application services. Internet changes the external marketing and internal collaboration, Yonyou help companies build new-generation digital marketing service system and new internal collaboration system. (3) Innovative business model. Yonyou will conduct direct cooperation with companies at value chain level and establish new cooperation relationship based on existing IT technology products and services.

\section{(4) Developmental tendency}

Service-based cooperation model seems to have a bright future. First, the model conforms to the requirements of the general trend of online-offline integration in the mobile internet era as the relationship between the online company and offline companies is relatively equal and open. Second, the model has a good "supply" basis, the numerous third party start-up companies attached to those closed Internet platforms may involve in such field. Third, the diffusion of the model in a business ecosystem helps to formalize pressure on close platform provider companies for business model innovations, which contributes to the healthy development of the entire business ecosystem.

\subsubsection{Element-based competition model}

\section{(1) Working definition}

Element-based competition model refers to the business model by which the online company (or $\mathrm{O} 2 \mathrm{O}$ offline company) form the competitive advantage over the offline companies by providing consumers (users) with alternative products and services. The online companies adopting this model do not "invade" (like platform-based integration model) or "embed" (like platform-based cooperation model) the value chain of offline companies, but build a substituted value chain. In general, this model is applicable to business fields where the offline contexts are weak. 


\section{(2) Context structure}

From the viewpoint of context management, the competiveness of the element-based competition model stems from two sources: high-degree virtual experience of online (digitized) contexts (i.e., in fields of mobile games, video sharing, etc.); second, the offline contexts, which tend to be relatively weak or even ignorable. All these make the model no needs to consider strategic problems accompanied with online-offline integration.

\section{(3) Strategic characteristics}

High competitive orientation. The model generally has a clear competitive goal, and tends to form a substitution-type competitive pressure over the targeted offline businesses/companies (e.g., mobile finance for traditional finance, and mobile reading for the traditional library), but at the same time, it has a relatively independent and complete value chain system of its own.

Strategic independence. Because the competitiveness of this model comes from its digital virtual scenario, there is a possibility that it can be regarded as a means to direct the traffic, and can be integrated into the platform integration / cooperative model system in theory. However, because the model itself does not have the contacts with the offline scenarios, the conversion efficiency and cost of its traffic have to be considered.

Typical cases. In 2013, China's first online insurance company, Zhong-An Online Property Insurance was jointly established by Alibaba, Tencent and Ping-An with the registered capital of RMB 1 billion. Alibaba is the largest shareholder (the shareholding ratio is 19.9\%), Tencent and Ping-An hold 15\% respectively, and are the second largest shareholder; the remaining $50 \%$ share is hold by 6 information technology or investment companies. Zhong-An Online broke through the existing domestic insurance business model, handling sales and claims completely through internet. Business medias revealed that Zhong-An Online would do business with its shareholders in the initial stage of operation as these large internet companies have huge insurance demand. We can see from this case that: (1) Alibaba intends to form an alternative effect over the traditional insurance businesses through online insurance model; (2) such online insurance model is not integrated into its own strategic framework of online-offline integration, but the "related diversification" in the broad sense with utilizing extra resources as the main purpose; (3) Alibaba and other large shareholders which are also internet platform providers, can stay together "harmoniously" because of the independence of the model compared with other three models.

\section{(4) Developmental tendency}

The element-based competition model is fundamentally an online digital context-based, substitution-type competitive strategy. Its development in future depends mainly on several internal and external factors. First, external factors such as the life cycle and maturity lead-time of the product, the industry chain structure of the model, and the development of related technologies; second, internal factors such as internal resources, accumulation of knowledge and matching degree. In general, the model is relatively isolated from the overall "Internet Plus" trend of the whole new internet economy. 


\subsection{Offline business model}

Offline companies can be divided into two categories according whether they adopted an online business models: (1) O2O model, when part of the offline company's business is under an online business model; (2) traditional model, when the offline company has not adopted any online business models.

$\mathrm{O} 2 \mathrm{O}$ model is undoubtedly superior to the traditional model, even only from the viewpoint of complying with the general trend of technological changes and SoLoMo. In addition, because the $\mathrm{O} 2 \mathrm{O}$ model means that the businesses of the offline companies can be divided into online and offline businesses, the model selection and logics of the online businesses are not so different from the "pure" online companies.

Table 2. Combinability of various types of business models in mobile Internet

\begin{tabular}{l|cccc}
\hline & $\begin{array}{l}\text { Platform-based } \\
\text { integration model }\end{array}$ & $\begin{array}{l}\text { Platform-based } \\
\text { cooperation model }\end{array}$ & $\begin{array}{l}\text { Service-based } \\
\text { cooperation model }\end{array}$ & $\begin{array}{l}\text { Element-based } \\
\text { competition model }\end{array}$ \\
\hline $\begin{array}{l}\text { Platform-based } \\
\text { integration model }\end{array}$ & + & - & - & + \\
$\begin{array}{l}\text { Platform-based } \\
\text { cooperation model } \\
\begin{array}{l}\text { Service-based } \\
\text { cooperation model }\end{array}\end{array}$ & - & + & + & + \\
$\begin{array}{l}\text { Element-based } \\
\text { competition model }\end{array}$ & - & + & + & + \\
\hline \multicolumn{1}{l}{ Weighted score } & + & + & 2 & + \\
\hline
\end{tabular}

Note: Score criteria, "+": 1, "-": - 1.

\section{Evolutionary Paths of the Mega Online-Offline Ecosystem}

Given changes in external technological environment and market competition, business ecosystems are moving from "old equilibrium" to "unbalance", and finally to "new equilibrium". All types of companies are expected to play an active role in this process of macro-level evolution. They hope to be able to provide consumers with better contextualization-based interaction services, and gradually enhance their positions in the competition and integration relationships with other types of companies. To this end, companies compete and cooperate by choosing and using different business context models, resulting in the change in the structure and the overall evolution of the business ecosystem.

\subsection{The combinability of business models}

A company can be seen as a business model or a collection of business models at a given 
temporal point. The company evolves by replacing the existing business model with a new business model. Both cases need to consider the combinability between the business models (mutual repellency with other models). Table 2 shows the combinability of various types of business models in the context of mobile internet. Element-based competition model has the highest combinability score (4), platform-based cooperation model and service-based cooperation model take the second place (2), while platform-based integration model has the lowest score because of its closed characteristic (0).

\subsection{Long-term competitiveness of major-type online/offline companies}

Given the general trend of "Internet Plus" of the entire economy and the integration between online and offline businesses, online and offline business models share some common tendencies, for example, from close to open, from competition to cooperation. The evolutionary features of the structure of business ecosystems, and the entire mega ecosystem, in the mobile internet era can be represented by the distinct trends of competition-cooperation within the ecosystem and across ecosystems. Hence, we summarize long-term competitive prospects of main online/offline companies (models), on the basis of the results of analysis on the competitiveness and developmental trends of the various business models in the previous section.

\subsubsection{Online companies (models)}

(1) Platform-based integration companies: The long-term competiveness of companies adopting the model is not optimistic, and the compositionality of the model is the worst. It means that the competitiveness of companies adopting the model tends to decline over time, and it is difficult for these companies to upgrade their business models (it is difficult to make gradual changes because the complexity of coordinating a variety of coexisting and mutually exclusive forces and interests on the platform).

(2) Platform-based cooperation companies: They have good developmental prospects, and the compositionality of the model is second best. Benefiting from the open source development trend in various industries and even the national economy, the cooperation platform will gradually undertake the dominant position of the current integration platform, and become the foundation of business ecosystems with cooperation as the fundamental logic.

(3) Element-based competition companies: The competitiveness of element-based competition model comes from the superiority of the online virtual contexts over the offline contexts. As the integration of online and offline contexts deepen, it is no doubt that the substitution advantages will show a trend of reduction. Although high online experience areas such as mobile gaming will still exist and might continue to grow, it is anticipated that the integration with offline contexts shall be taken into consideration sooner or later (for example, enhancing the mobile gaming technology by further embedding into offline real time).

(4) Service-based cooperation companies: the model has better prospects for long-run 
development because of its online-offline cooperative relationships at a high level. Different from the platform-based cooperation model which is mainly adopted by large internet companies, the model has broader applicable range, even including companies from software service industry. Under the pressure of internetization in various industries, it is urgent for service providers to upgrade their service to meet this trend. In this sense, competition among service-based cooperation companies will be increasingly fierce. However, due to the bright developmental prospects and combinability of the model, the long-term competitiveness of companies adopting the model will be on the rise.

\subsubsection{Offline companies (models)}

(1) $\mathrm{O} 2 \mathrm{O}$ companies: As mentioned above, the $\mathrm{O} 2 \mathrm{O}$ model combine advantages from both the online business model and resource stock of offline companies to formalize synergistic effect. Therefore, the long-term developmental potential of $\mathrm{O} 2 \mathrm{O}$ companies tends to be on the rise. On the other hand, the population of $\mathrm{O} 2 \mathrm{O}$ companies presents a very large diversity. In other words, due to the difference in strategic choices regarding online business models, vertical application areas and etc., the competitiveness difference among $\mathrm{O} 2 \mathrm{O}$ companies will be very obvious.

(2) Traditional companies: Under the dual pressure from online companies and from internetized offline companies (O2O companies), the market space of traditional offline companies will be further suppressed. In this respect, traditional companies tend to have a declining competitiveness in long run.

\section{Concluding Remarks}

In the context of new internet economy, business and consumption are facing a new question, how to achieve "omni channel", two-way integration between online and offline, to shape business ecosystems with significant value creating tendency. In the context of China, contextualization is the core power for the evolution of business model and ecosystem under the background of mobile internet. We analyzed structural features, competitive characteristics, typical cases and developmental prospects of main business models in the current situation. On the basis of this, we further evaluated evolutionary characteristics of the business ecosystem. "Competition, openness and cooperation" is the general trend of business development in the new era of mobile Internet. Given the complexity of contextual issues of business model and the ecosystem evolution, it is crucial for relevant stake-holders (e.g., companies, governments, consumers and mass media) to collectively formalize basic rules by which most online-offline ecosystems can evolve towards a virtuous direction. 


\section{References}

Dess, G. G. and Davis, P. S. (1984) "Porter's (1980) generic strategies as determinants of strategic group membership and organizational performance", Academy of Management journal, vol. 27, no. 3, pp. 467-488.

Etemad, H., Wilkinson, I. and Dana, L. P. (2010) "Internetization as the necessary condition for internationalization in the newly emerging economy", Journal of International Entrepreneurship, vol. 8, no. 4, pp. 319-342.

Hong, Y. (2017) "Pivot to Internet Plus: Molding China's digital economy for economic restructuring?", International Journal of Communication, vol. 11, pp. 1486-1506.

Huang, J. S., Pan, S. L. and Liu, J. (2017) "Boundary permeability and online-offline hybrid organization: A case study of Suning, China", Information \& Management, vol. 54, no. 3, pp. 304-316.

Iansiti, M. and Levien, R. (2004) Keystones and dominators: Framing operating and technology strategy in a business ecosystem, Boston: Harvard Business School.

Moore, J. F. (1993) "Predators and prey: A new ecology of competition", Harvard Business Review, May/June, pp. 75-86.

Scoble, R. and Israel, S. (2014). Age of context: Mobile, sensors, data and the future of privacy, Patrick Brewster Press.

Thomas, L. D. and Autio, E. (2013) "The fifth facet: The ecosystem as an organizational field", Innovation and Entrepreneurship Group Working Papers, 1-40.

Wang, Z., Chen, C., Guo, B., Yu, Z. and Zhou X. (2016) "Internet plus in China", IT Professional, vol. 18, no. 3, pp. 5-8.

Yang, G., and Wang, R. (2013) "The institutionalization of an electronic marketplace in China, 1998-2010”, Journal of Product Innovation Management, vol. 30, no. 1, pp. 96-109. 